\title{
The Welfare Consequences of Tariff Rebalancing in the Domestic Gas Market
}

\author{
ANDRES GOMEZ-LOBO'
}

\section{INTRODUCTION}

The domestic energy markets in the United Kingdom are still in a process of structural change. Earlier this year, limited competition for the supply of household domestic gas was introduced, with full-scale competition expected to develop in the next few years. Competition for the supply of electricity to households is expected to begin in 1998.

The introduction of competition in the supply of these energy goods will force tariffs to become more cost-reflective. Until now, maintaining cross-subsidies between consumer groups has not posed any difficulties, given that the suppliers of electricity as well as British Gas have enjoyed monopoly concessions. Profits lost by subsidising one group of consumers have been compensated by higher price-over-cost margins for other groups. Competition is likely to change this. New

\footnotetext{
${ }^{1}$ Department of Economics, University College London, and the Institute for Fiscal Studies.

The author would like to thank Ian Preston and an anonymous referee for their excellent comments and suggestions. He would also like to thank participants at OXERA's Energy Modelling Group meeting for their comments on an earlier version of this paper. The results presented here are a summary of research on energy demand modelling undertaken by the ESRC Centre for the Microeconomic Analysis of Fiscal Policy at the Institute for Fiscal Studies. Material from the Family Expenditure Survey, made available by the Central Statistical Office through the ESRC Data Archive, has been used by permission of the Controller of HMSO. Neither the CSO nor the ESRC Data Archive bears responsibility for the analysis or the interpretation of the data reported here. The usual disclaimer applies.
} 
entrants will try to target market segments where current prices are above supply costs and will have no incentive to supply groups where costs are above prices. To survive, incumbents - who have universal services obligations - will be forced to end internal cross-subsidies.

There is a presumption that one of the most important cross-subsidies present in the current pricing structure for energy goods is the balance between the standing charge (which is independent of the amount of energy consumed) and the unit price of energy. ${ }^{2}$ The fixed costs of supplying a household, in terms of metering and billing expenses, are above the standing charge. On the other hand, the price for each unit of energy is above the supply costs. As competition takes hold in these markets, we would expect a rebalancing to occur between the two components of energy prices. The standing charge will probably rise relative to the unit energy price.

The rebalancing of the fixed and variable charges might be justified on efficiency grounds - or at least might be unavoidable in a competitive market but the distributional consequences could be a cause for concern. ${ }^{3}$ Energy goods are necessities and as such they represent a higher proportion of the expenditure of low-income households. Price increases for these goods have the same distributional effects as regressive taxation. Furthermore, since low-income households also purchase lower amounts of energy, the standing charge represents a higher proportion of their total energy bill. Thus tariff rebalancing is more likely to have a negative impact on lower-income households. The savings due to the lower unit price will be applied to a smaller level of energy consumption and will not compensate for the increase in the standing charge.

This adverse distributional impact may explain why regulators in these industries are reluctant to allow an increase in the fixed charge. In the case of gas, there has been a supplementary price cap applied to the fixed-charge element of gas prices. This is in addition to the well-known RPI-X cap applied to gas revenues as a whole. Also. it seems that Ofgas has implicitly sanctioned the preservation of some level of cross-subsidy in gas prices by setting the fixed charge for TransCo (the gas transporting company) below what British Gas and competitors expected (Hancock and Waddams Price, 1995).

\footnotetext{
2This is by no means the only cross-subsidy present in the current tariff structure. There are also regional cross-subsidies, especially in the case of gas. The most important cross-subsidy cited by industry sources occurs between consumers who are prompt payers and those who are late payers. This last group accounts for a significant proportion of customer-related costs, but until recently both groups have faced the same tariffs.

3 Independent of welfare considerations, cost-reflective two-part tariffs are not always efficient. If sufficient consumers opt to disconnect from the service when the fixed charge rises. it might be more efficient to maintain a low standing charge. See Feldstein (1972) and Schmalensee (1981).
} 
The relation between energy prices and welfare has been analysed in Hancock and Waddams Price (1995) and Burns, Crawford and Dilnot (1995). These studies confirm that poorer households are more vulnerable to changes in energy prices. Unlike these previous studies, in the present paper we use an econometric model of household consumption behaviour to examine these issues. Thus our model allows for behavioural responses to price changes. This should yield more precise and quantitative welfare results than those in previous studies.

In particular, published information on the possible magnitude of the cross-subsidy in current gas tariffs is used to construct several scenarios of price changes. We then examine the welfare consequences of each scenario. The results show that the majority of households would gain from tariff rebalancing, although there is a significant group that would be made worse off. Furthermore, the latter group is composed of poorer and more vulnerable households. However, we show that if competition reduces customer-related costs by between 20 and 30 per cent, then almost all households stand to gain.

Our results would seem to suggest that the misgivings of consumer groups and the regulator with respect to tariff rebalancing may be exaggerated if the rebalancing is accompanied by an increase in efficiency and a decrease in the overall tariff level. However, if the potential cost savings that may be achieved in a competitive market are below the 20-30 per cent range mentioned above, then tariff rebalancing does pose distributional conflicts.

The paper is organised as follows. The next section briefly discusses the demand model, the data and the estimation results. Section III estimates the welfare effects and Section IV concludes.

\section{HOUSEHOLD ENERGY DEMAND MODEL}

\section{The QUAIDS Demand Model}

In this paper, the demand model estimated by Gómez-Lobo (1996) is used. Household preferences were represented by the QUAIDS utility function of Banks, Blundell and Lewbel (1996). This utility function is flexible enough to portray a wide range of consumption patterns and elasticities, and has some other appealing characteristics which will be discussed below. Before welfare analysis can be undertaken, the parameters of this utility function must be estimated. This is done by first deriving the demand equations from the utility function. The parameters of the demand system (which are directly related to the parameters of the utility function) can then be estimated from observed expenditure data.

The demand system consists of six goods: electricity, gas, food, clothing, alcohol and a category for all other non-durable non-housing expenditures. One of the most appealing characteristics of the QUAIDS model is that the share of expenditure on 


\section{FIGURE 1}

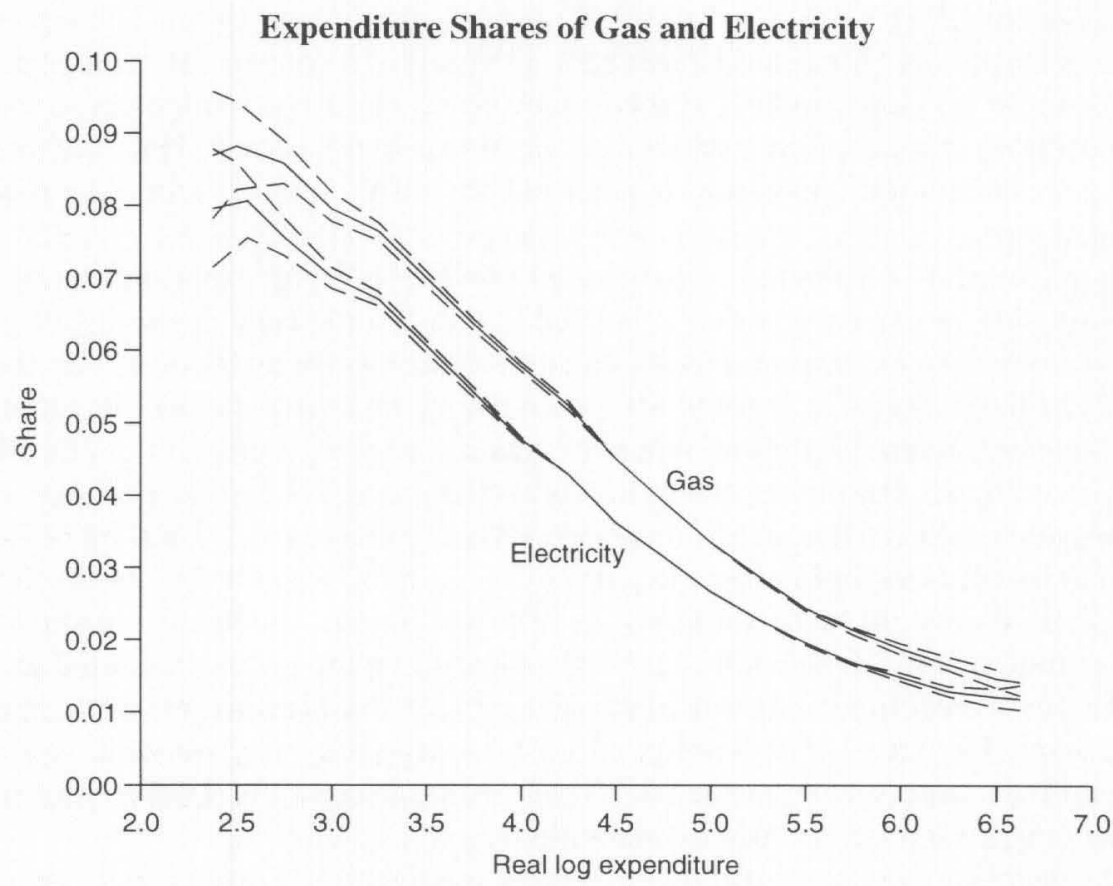

a particular good is a quadratic function of the logarithm of real total expenditure. An informal assessment of the data (see Figure 1) is supportive of a linear or quadratic relationship between the expenditure shares and the logarithm of real expenditure. ${ }^{\ddagger}$ Therefore the demand system we estimate has a functional form that appears to be consistent with the data.

\section{Data}

The model was estimated using data from the Family Expenditure Survey (FES) from 1985 to 1993 . The FES is a yearly random survey of about 7,000 households in the UK. It contains detailed information on household expenditure, income, ownership of durables, demographic characteristics and other variables. Particularly important for the present study is the information on electricity and gas supply connections to the household's dwelling, gas and electricity expenditure,

\footnotetext{
+ The Engel curves of Figure 1 are non-parametric adaptive kernel estimates. The dashed lines are the bounds of the 95 per cent confidence intervals.
} 
mode of payment of gas and electricity bills, type of central heating and the holdings of energy-using durables.

There is also information in the FES on other domestic fuels such as coal and oil. However, modelling the consumption of these alternative fuels is difficult. They are usually purchased in large quantities and stocked. In our sample, we observe a few households with large expenditures that do not reflect their consumption during the fortnight of the survey. Conversely, some households that have zero expenditure may be consuming these fuels but were not observed purchasing any during the survey period. In the case where all households consume some of these fuels, this infrequency of purchase problem could be overcome (see Meghir and Robin (1992)). However, in our sample, there are many households that are genuine non-consumers of coal and oil, and there is no way of distinguishing them from those households that consume but are not observed purchasing the product. For this reason, other domestic energy goods besides gas and electricity are ignored. Due to the decreasing importance of these fuels in the late 1980s, this omission should not significantly bias the results.

The total sample includes 55,959 observations, of which 12,498 did not have a gas supply connection. ${ }^{5}$ There are several categories of consumers: those paying standard tariffs, either through an automatic bank debit system or through a periodic bill, and those who have a prepayment meter installed and pay a special tariff. Only a small percentage of consumers have prepayment meters.

For those consumers paying through a direct debit system, the recorded expenditure does not necessarily coincide with their actual consumption for that quarter. This is because the direct debit arrangement is used to smooth expenditure over the year. The amount debited from the customer's bank account each month is an estimate of the average yearly consumption rather than actual consumption during the period. Fortunately, the FES also records the information from the last gas and electricity advice. The advice records the true consumption by the household during the period and differs from the actual direct debit payment. The advice figures were used as the relevant expenditure for those households that paid through a direct debit system.

One of the novelties of the database is the use of two-part tariff information for gas and electricity instead of the aggregate price indices for these goods from the retail price index (RPI). Actual tariffs, disaggregated by region and by fixed and

\footnotetext{
${ }^{5}$ Almost 100 per cent of households had electricity connections. The few that did not were dropped from the sample. Those households with zero electricity expenditures were dropped too. Also, observations from Northern Ireland were excluded from our sample

${ }^{6}$ Although this last group pays a special tariff. it was included in the standard credit group.
} 
variable charge, were obtained from British Gas and the Electricity Association. For the other four goods, price indices were constructed using indices from the RPI.

Since the recorded energy expenditures during the interview period of the FES usually refer to consumption that occurred in the last quarter, prices for electricity and gas have been lagged three months. The fixed charge for each of the energy goods was subtracted from the expenditure on these goods. Total expenditure was the sum of these net expenditures plus the expenditure on the four other non-energy goods.

The other conditioning variables included regional dummies, cohort dummies, tenure type, number of rooms in the dwelling, ownership of washing machine, presence of gas or electricity central heating, monthly dummies, number of adults in the household, number of retired persons in the household, number of females in the household, number and age of children in the household, a dummy variable that reflects whether part of the energy expenditures is paid through the rent, and a trend. We also included a temperature variable - the quarterly average of mean daily air temperature at sea level recorded by the Meteorological Office. There are two temperature series — one for Scotland and the other for England and Wales. Households were assigned one or the other depending on the region in which they reside.

\section{Estimation Results}

Before presenting the estimation results, it is important to discuss certain features of the domestic energy markets that must be addressed in order to obtain unbiased estimates.

In the sample, 22 per cent of households did not have a connection to the gas supply grid and therefore relied almost exclusively on electricity. Therefore there are many gas shares that are zero and this biases the estimation results when the full sample is used. One approach to overcome this problem is to use only those observations that have a positive amount of consumption - that is, to estimate the share equations using as observations only those households that have gas connections. However, this does not by itself lead to unbiased estimates. Intuitively, the problem is that, in the subsample of observations with positive gas shares, there will be an over-representation of households that have a strong 'taste' for gas consumption. Households with a strong 'taste' for gas will be more likely to be

\footnotetext{
${ }^{7}$ There is an issuc about the correct way to deal with the irresolvable problem of differently dated expenditures. An alternative specification that was tried was to lag the prices for all goods by one quarter. However. the specification presented in this paper seemed to give the best results, and was therefore chosen as the preferred model.
} 
connected to the gas network. Not accounting for this selectivity problem will lead to biased parameter estimates.

To solve this problem, the popular two-step Heckman correction technique is used (Heckman, 1979). We will outline this approach without going into technical details. In the first step, the gas connection decision is modelled through a probit equation based on a set of variables that should influence this decision. ${ }^{8}$ With the estimates from the probit equation, a new variable is formed for each household the hazard rate, $\lambda$ - and this new variable is added to the share equations as an additional regressor. Then the demand system can be estimated using only those observations that are connected to the gas supply network. The hazard rate controls for the fact that preference for gas consumption will be higher within the subsample of gas-connected households than in the overall sample."

Energy goods, such as electricity or gas, are usually sold using two-part tariffs." There is a quarterly standing charge, which is independent of the amount of energy consumed, and a variable price per unit of energy.

Non-linear prices create kinks in a consumer's budget constraint and may induce discrete (non-marginal) responses to price changes. For example, in the two-part tariff case, when the variable price of the good increases, an individual may prefer to forgo consumption altogether, and thus save the fixed charge, rather than reduce his consumption marginally. Non-linear pricing creates a number of econometric problems (see Moffitt (1990)).

Fortunately, in the case of two-part tariffs (which is a special case of non-linear pricing), the econometric problems are very similar to those raised by the connection decision discussed above. The presence of a standing charge makes a consumer ponder whether it is worth purchasing or connecting at all. Therefore the two-step selectivity correction approach outlined above is sufficient to correct for biases arising from the two-part tariff structure of energy goods. "Care, however, must be taken in defining the shares and the prices to use in the estimation. The expenditure on goods should exclude the standing charge, and shares and total

\footnotetext{
${ }^{8}$ In many cases, the household does not make a voluntary decision with respect to the connection to the gas inain. For example, a particular houschold might live in an area withoul a gas supply grid. Regional dummies and other variables are included in the probit equation to control for these non-voluntary non-connections.

${ }^{9}$ In order to identify the coefficient for the $\lambda$ variable in the share equations, there must be a variable in the probit equation that is not included in the share equations. This identifying variable was the ratio of the fixed charge of gas to the fixed charge of electricity.

${ }^{10}$ Some energy tariffs in the UK are more complex than a two-part tariff. However, the majority of consumers of domestic gas and electricity face two-part tariffs.

${ }^{11}$ Although the use of the two-step selectivity correction technique should lead to unbiased estimates, the complications posed by non-linear prices must still be addressed when using the model to simulate responses to price changes. This will be discussed further below.
} 
TABLE 1

Gas and Electricity Share Equations with Symmetry Imposed

\begin{tabular}{|c|c|c|c|c|}
\hline \multirow[b]{2}{*}{ Variable } & \multicolumn{2}{|c|}{ Gas share equation } & \multicolumn{2}{|c|}{ Electricity share equation } \\
\hline & Parameter & tstatistic & Parameter & t statistic \\
\hline Constant & 0.1638 & 19.42 & 0.1956 & 28.66 \\
\hline North & 0.0121 & 9.04 & -0.0049 & 4.45 \\
\hline Yorkshire & 0.0168 & 10.30 & -0.0045 & 3.42 \\
\hline North West & 0.0186 & 9.75 & -0.0027 & 1.81 \\
\hline East Midlands & 0.0108 & 7.56 & -0.0056 & 4.82 \\
\hline West Midlands & 0.0130 & 8.43 & -0.0033 & 2.60 \\
\hline East Anglia & -0.0020 & 2.18 & -0.0031 & 4.17 \\
\hline London & 0.0175 & 8.65 & -0.0038 & 2.32 \\
\hline South West & -0.0022 & 2.77 & -0.0012 & 1.90 \\
\hline South East & 0.0088 & 6.46 & -0.0029 & 2.65 \\
\hline Wales & 0.0031 & 3.15 & -0.0017 & 2.04 \\
\hline Number of rooms & 0.0036 & 29.27 & 0.0017 & 17.52 \\
\hline Gas central heating & 0.0194 & 53.95 & -0.0078 & 26.54 \\
\hline Electric central heating & -0.0072 & 8.70 & 0.0178 & 26.42 \\
\hline Washing machine & 0.0061 & 10.53 & 0.0033 & 7.03 \\
\hline Fridge & 0.0014 & 1.00 & 0.0084 & 7.44 \\
\hline Paid in rent & -0.0019 & 9.82 & -0.0008 & 5.09 \\
\hline Temperature $_{t-3}$ & -0.0016 & 10.54 & -0.0002 & 1.49 \\
\hline Trend & -0.0001 & 3.15 & -0.0000 & 0.91 \\
\hline Owned & 0.0115 & 11.19 & -0.0020 & 2.44 \\
\hline Rent-free & -0.0007 & 0.45 & 0.0032 & 2.52 \\
\hline Council & 0.0073 & 8.67 & 0.0011 & 1.68 \\
\hline Gas price $_{t-3}$ & 0.0145 & 2.21 & -0.0143 & 4.07 \\
\hline Electricity price $_{t-3}$ & -0.0143 & 4.70 & 0.0052 & 1.78 \\
\hline Food price & -0.0343 & 2.82 & -0.0268 & 3.27 \\
\hline Clothing price & -0.0078 & 0.83 & 0.0000 & 0.00 \\
\hline Alcohol price & 0.0342 & 2.84 & 0.0134 & 1.90 \\
\hline Expenditure & -0.0526 & 22.83 & -0.0537 & 28.61 \\
\hline Expenditure $^{2}$ & 0.0025 & 10.26 & 0.0033 & 16.88 \\
\hline$\lambda$ & 0.0442 & 10.43 & -0.0056 & 1.63 \\
\hline Number of observations & \multicolumn{4}{|c|}{40,431} \\
\hline Average sample share & \multicolumn{2}{|c|}{ Gas $=0.0446$} & \multicolumn{2}{|c|}{ Electricity $=0.0366$} \\
\hline
\end{tabular}


Notes to Table 1

Results for cohort, month and the number of children, adults, females and retired persons in the household are not reported. This information, as well as the results for the other four equations, is available from the author upon request.

The share of the energy good, as well as total expenditure, is net of the weekly fixed charges.

Symmetry imposed through minimum-distance estimator. The Amemiya statistic for symmetry restriction, $\chi_{10}^{2}$, was 38.14 .

The constant for the price deflator, $\alpha_{0}$, was set to zero.

expenditure should be defined accordingly. Also, the price of domestic fuels in the share equations should be the variable price only.

The results for the gas and electricity equations are presented in Table $1 .^{12,13}$

Households in most regions of England and Wales have a tendency to consume more gas than their counterparts in Scotland (the omitted dummy). The reverse is true for electricity, pointing to the predominance of electricity as an energy source in Scotland. Household characteristics, especially the type of central heating, are an important determinant of energy expenditure. In the case of electricity, we were able to control for the presence in the household of a washing machine and a fridge and/or freezer, both of which have the expected positive effect on electricity expenditure. A dummy variable for those households that paid services in their rent or communal charge has the expected sign, since part of their energy expenditure is paid indirectly. The temperature variable is lagged one quarter and has the expected negative sign.

The hazard rate, $\lambda$, was significantly positive in the gas equation. This is consistent with people connected to the gas network having an above-average preference for gas consumption; estimates that do not take account of this phenomenon will give biased results.

The parameters on the price variables merit some discussion. The own-price coefficients in both equations are positive and, in the case of electricity, not significantly different from zero (at a 95 per cent significance level). A positive or zero coefficient is not inconsistent with negative own-price elasticities, since the dependent variable is the share of the good in total expenditure. For goods that have inelastic demands, the quantity purchased will decrease with a price increase while the share in total expenditure none the less rises.

\footnotetext{
12 To be consistent with consumer demand theory, the estimated demand system must be symmetric - that is, the cross-price effects between equations must be equal. Symmetry was imposed on initial estimated parameters using a one-step minimum-distance estimator. This restriction was rejected by the data, as can be seen from the Amemiya statistic presented in the notes to Table 1 . Other specifications were also tried (in one case, prices for all goods were lagged one quarter) without an improvement in the Amemiya statistic.

${ }^{13}$ Although the model was estimated for six goods, only the results for the energy good equations are presented here. The results for the other equations are available from the author upon request.
} 
TABLE 2

Weighted Average of Individual Elasticities

\begin{tabular}{l|rrrrr}
\hline & Gas & Electricity & Food & Clothing & Alcohol \\
\hline Compensated elasticity & & & & & \\
Gas & -0.29 & -0.13 & -0.23 & -0.33 & 0.62 \\
Electricity & -0.13 & -0.56 & -0.10 & -0.11 & 0.05 \\
Food & -0.02 & -0.01 & -0.13 & 0.21 & 0.08 \\
Clothing & -0.12 & -0.04 & 0.75 & -1.41 & -0.55 \\
Alcohol & 0.41 & 0.03 & 0.42 & -0.94 & -2.63 \\
Uncompensated elasticity & & & & & \\
Gas & -0.31 & -0.14 & -0.31 & -0.34 & 0.62 \\
Electricity & -0.15 & -0.57 & -0.22 & -0.13 & 0.04 \\
Food & -0.05 & -0.03 & -0.37 & 0.15 & 0.04 \\
Clothing & -0.17 & -0.08 & 0.30 & -1.55 & -0.64 \\
Alcohol & 0.35 & -0.02 & -0.10 & -1.08 & -2.73 \\
Budget elasticity & 0.17 & 0.31 & 0.67 & 1.39 & 1.55 \\
\hline Not: Indvis
\end{tabular}

Note: Individual elasticities are aggregated using household expenditures as a share of total sample expenditures as weights.

The cross-price terms indicate that electricity and gas are complements, food is a complement to both energy goods and alcohol is a substitute for both energy goods. The complementarity between gas and electricity is not at all surprising, given that we are assuming that the ownership of energy-using durables is fixed. Most electricity-using appliances (such as lighting, kitchen appliances and televisions) are used in household activities where one would also expect gas-using appliances to be used (gas cookers, gas central heating and gas water heating).

Table 2 presents the average compensated, uncompensated and budget elasticities for all equations. The compensated elasticities show the response of consumers under the hypothetical case that they are compensated for the real income change that a price increase will produce. It is clear that the demands for both gas and electricity are inelastic with respect to their own price. The budget elasticities also show that these goods are necessities over the range of expenditures present in the sample. 


\section{WELFARE CALCULATIONS}

In this section, we apply the model results to estimate the welfare impacts of tariff rebalancing in the domestic gas market. It is difficult to establish the exact magnitude of the cross-subsidy. We use the information contained in Burns, Crawford and Dilnot (1995). Using information from primary sources, they establish that customer-related costs of British Gas are of the order of $\mathfrak{E} 65$. The standing charge is only $£ 37$, implying that a significant ( 76 per cent) increase in this price would be necessary to reflect costs. On the other hand, the commodityrelated costs are estimated to be close to 39 pence per therm, 12 per cent below the 43.8 pence per therm charged by British Gas. Assuming these numbers reflect, approximately, the magnitude of the cross-subsidy, we will analyse the welfare impact of three scenarios. The first — the baseline scenario — reflects the information presented above and corresponds to a total rebalancing of tariffs. The other two scenarios involve a higher and lower decrease in the unit price but constrain the profits of British Gas to be the same as in the baseline case. The three cases analysed are the following:

1. a 76 per cent increase in the standing charge and a 12 per cent decrease in the unit price;

2. a 50 per cent increase in the standing charge and an 8 per cent decrease in the unit price;

3. a 105 per cent increase in the standing charge and a 16 per cent decrease in the unit price.

As a welfare measure, we use the compensating variation. It corresponds to the amount of monetary resources that must be given to a household after a price change in order for that household to be able to obtain the same utility level that it enjoyed before the change. Since the parameter estimates from the demand system are also the parameters of the utility function, we are able to estimate the compensating variation for each household. We do this for observations in the final year of the dataset (1993).

The results are presented in Table 3 . The majority of households have a negative compensating variation. This means that income must be taken away from these households in order for them to have the same level of welfare as before the price change. In other words, these households are better off after the tariff rebalancing than before. The negative effects of the rise in the fixed charge are more than compensated by the savings due to the fall in the variable price.

All scenarios presented above are roughly profit-neutral. ${ }^{14}$ Profit neutrality implies that some consumers must lose from the tariff change, since someone has to pay for the lower expenditure of the winners. It can be seen from Table 3 that there is a significant group of households that are hurt by the tariff changes. 
TABLE 3

Welfare Effects of Tariff Rebalancing

\begin{tabular}{l|cccc}
\hline Scenario & $\begin{array}{c}\text { Number of } \\
\text { households } \\
\text { with positive } \\
\text { compensating } \\
\text { variation }\end{array}$ & $\begin{array}{c}\text { Number of } \\
\text { households } \\
\text { with negative } \\
\text { compensating } \\
\text { variation }\end{array}$ & $\begin{array}{c}\text { Total number } \\
\text { of households }\end{array}$ & $\begin{array}{c}\text { Change in } \\
\text { gas } \\
\text { consumption } \\
\text { (therms per } \\
\text { week) }\end{array}$ \\
\hline $\begin{array}{l}\text { Case 1: } \\
76 \% \text { increase in standing charge } \\
12 \% \text { decrease in unit price }\end{array}$ & 1,496 & 2,964 & 4,460 & 2,214 \\
$\begin{array}{l}\text { Case 2: } \\
50 \% \text { increase in standing charge }\end{array}$ & 1,489 & 2,999 & 4,488 & 1,450 \\
$8 \%$ decrease in unit price & & & & \\
$\begin{array}{l}\text { Case 3: } \\
105 \% \text { increase in standing charge } \\
16 \% \text { decrease in unit price }\end{array}$ & 1,586 & 2,863 & 4,449 & 2,940 \\
\hline
\end{tabular}

Notes: Calculations were made for the observations in the final year of the dataset (1993) and for which the expenditure function was increasing in the gas price. In each scenario, high income observations that had negative predicted shares were dropped. This explains the slight variation in the total number of households in each scenario. A positive compensating variation implies that the household is worse off after the price change than initially; the opposite is true for a negative compensating variation.

The issue of non-marginal responses when households face a non-linear budget constraint must be addressed at this point. The results of Table 3 overestimate the welfare impacts of those households that have a positive compensating variation. This is because some of these households might opt to disconnect from the service instead of bearing the full cost of tariff rebalancing. This, however, does not imply that the results of Table 3 are too extreme. It is true that the compensating variation for those households that decide to disconnect is overestimated. However, the revenues lost from these households must be recovered from those that stay in the market. Therefore tariffs would have to increase further than we have considered so far if the price change is to be profit-neutral. This would entail additional welfare losses for other households.

Figure 2 plots the compensating variations (for case 1) against total expenditure. It is clear from the graph that there is a negative relation between the compensating variation and the initial expenditure level. Higher-expenditure households tend to

\footnotetext{
${ }^{14}$ If they were not, the tariff changes would imply decreases (or increases) in the average price of gas. The welfare inference would then be a mixture of the effects of tariff rebalancing and the effects of a general price change.
} 


\section{FIGURE 2}

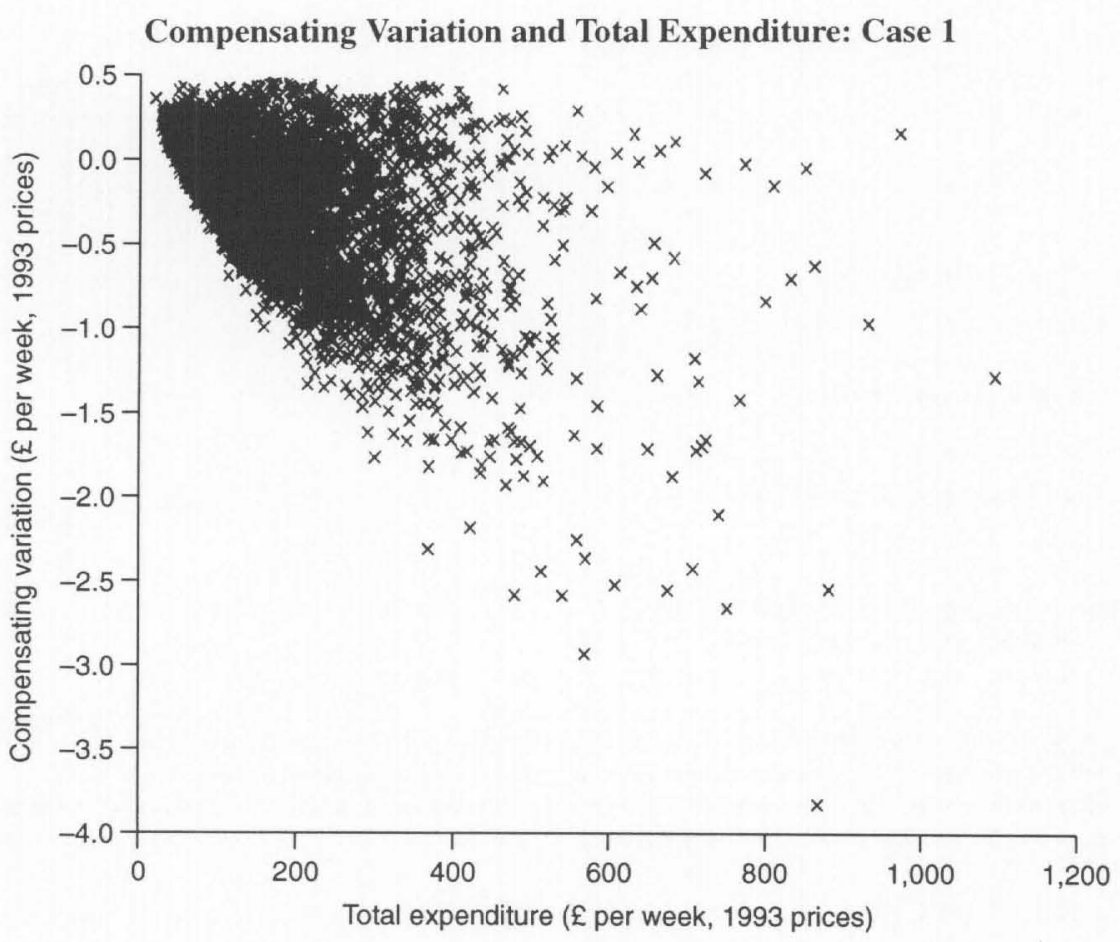

gain from the tariff rebalancing while lower-expenditure households are disproportionately the ones that suffer. This is not surprising, since higher expenditure is associated with a higher consumption of gas (although the share of expenditure on gas decreases with total expenditure). The rise in the fixed charge affects all households by the same amount, while the saving due to the decrease in the unit price is greater for households with high consumption levels.

To analyse in more detail who the winners and losers are, Table 4 presents the results for stratified subsamples of the data.

The regressive nature of the price changes - already observed in Figure 2 can be seen by observing the impact by quintile. On average, households in the first quintile (the poorest 20 per cent of the sample) suffer a welfare loss. In general, households that consume low amounts of gas will suffer from the rebalancing of tariffs, since the standing charge is a larger fraction of their overall bill. Therefore households with characteristics that are associated with higher gas expenditure, such as the presence of children or higher total expenditure, will have a lower (and usually negative) compensating variation.

The welfare impacts also differ according to the position in the life cycle of the head of the household. On average, when the head of the household is middle-aged 
TABLE 4

Average Compensating Variation for Different Groups

Pounds per week, 1993 prices

\begin{tabular}{l|ccccc|c}
\hline & \multicolumn{7}{|c|}{ Expenditure quintile } & \multirow{2}{*}{ All } \\
\hline Retired persons in household & $I$ & 2 & 3 & 4 & 5 & -0.15 \\
No retired persons in household & 0.06 & -0.12 & -0.25 & -0.38 & -0.54 & -0.15 \\
Household head aged under 25 & 0.07 & -0.09 & -0.21 & -0.31 & -0.52 & -0.25 \\
Household head aged 25-65 & 0.09 & -0.02 & -0.12 & -0.06 & -0.28 & -0.02 \\
Household head aged over 65 & 0.06 & -0.10 & -0.22 & -0.32 & -0.53 & -0.27 \\
No children in household & 0.06 & -0.11 & -0.24 & -0.41 & -0.50 & -0.10 \\
Children in household & 0.07 & -0.09 & -0.20 & -0.31 & -0.42 & -0.15 \\
All & 0.03 & -0.12 & -0.26 & -0.34 & -0.62 & -0.34 \\
\hline
\end{tabular}

Notes: Calculations were made using the compensating variation of the baseline scenario (case 1).

Each cell contains the average compensating variation for those households in that group.

A positive compensating variation implies that the household is worse off after the price change than initially; the opposite is true for a negative compensating variation.

(between 25 and 65), the compensating variation is lower than is the case for younger or older heads of households.

The results of Table 3 show that a significant group of households stand to lose from tariff rebalancing. Furthermore, the poor and old would be one of the most vulnerable groups affected. These results are not particularly new (see Burns, Crawford and Dilnot (1995) and Hancock and Waddams Price (1995)). However, with the results of the present study, some additional questions can be answered with respect to the welfare impacts of tariff rebalancing.

First, how important are the welfare losses for the households that are negatively affected in comparison with the welfare gains of the others? Figure 3 shows the distribution of the compensating variations for the price changes of case 1. The positive compensating variations are small in comparison with the negative compensating variations. This implies that the winners gain more than the losers suffer and thus, potentially, the winners could compensate the latter group and still have a positive net welfare gain. This is just a reflection of the efficiency of marginal cost pricing.

Another interesting question refers to the combined effect of tariff rebalancing and general price cuts that competition might produce. There is evidence that the introduction of competition in the industrial gas market reduced prices by between 


\section{FIGURE 3}

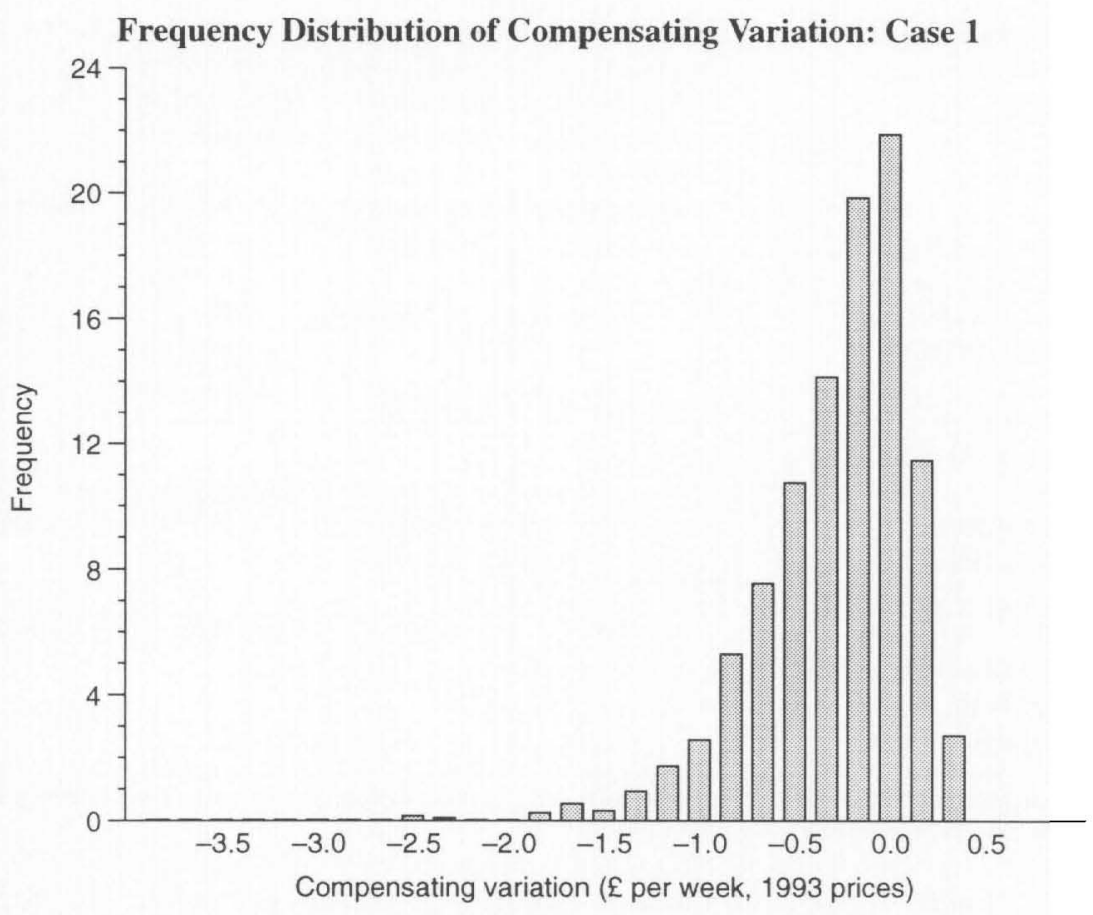

10 and 15 per cent (House of Commons, 1994). Some independent suppliers have declared that they will be able to substantially reduce the standing charge for domestic gas customers (House of Commons, 1994) once they are allowed to supply in a competitive market. In addition, the regional electricity companies are entering the gas supply market and there may soon be an integrated domestic energy charging system. This could produce significant economies in billing and other customer-related costs. Therefore it is not unrealistic to assume that cost savings could be achieved once competition in the supply of gas intensifies. The crucial question is "how large would these cost savings have to be in order to benefit those consumers who lose from the tariff rebalancing?'.

Table 5 shows the effects of tariff rebalancing (case 1) combined with alternative price reductions. The first three cases assume that competition will reduce customer-related costs by 10 per cent, 20 per cent and 30 per cent, respectively, and that these cost reductions are passed on to consumers in the form of lower fixed charges. The final case assumes that customer-related costs are reduced by 20 per cent and commodity-related costs are reduced by 10 per cent. It is clear that, if competition is able to reduce customer-related costs (from the current $£ 65$ ) by 
TABLE 5

Net Welfare Effects of Tariff Rebalancing (Case 1) Combined with Cost Reductions

\begin{tabular}{l|cccc}
\hline Scenario & $\begin{array}{c}\text { Number of } \\
\text { households } \\
\text { with positive } \\
\text { compensating } \\
\text { variation }\end{array}$ & $\begin{array}{c}\text { Number of } \\
\text { households } \\
\text { with negative } \\
\text { compensating } \\
\text { variation }\end{array}$ & $\begin{array}{c}\text { Total number } \\
\text { of households }\end{array}$ & $\begin{array}{c}\text { Change in } \\
\text { gas } \\
\text { consumption } \\
\text { (therms per } \\
\text { week) }\end{array}$ \\
\hline $\begin{array}{l}\text { Case 4: } 10 \% \text { decrease in } \\
\text { customer-related costs }\end{array}$ & 767 & 3,693 & 4,460 & 2,229 \\
$\begin{array}{l}\text { Case 5: } 20 \% \text { decrease in } \\
\text { customer-related costs }\end{array}$ & 310 & 4,150 & 4,460 & 2,242 \\
$\begin{array}{l}\text { Case 6: } 30 \% \text { decrease in } \\
\text { customer-related costs }\end{array}$ & 65 & 4,395 & 4,460 & 2,257 \\
$\begin{array}{l}\text { Case 7: } 20 \% \text { decrease in } \\
\text { customer-related costs, } \\
\begin{array}{l}10 \% \text { decrease in } \\
\text { commodity-related costs }\end{array}\end{array}$ & 63 & 4,363 & 4,426 & 3,861 \\
\hline
\end{tabular}

Note: Calculations were made using the tariff rebalancing scenario of case 1. Obviously, the cases presented in this table are not revenue-neutral.

between 20 and 30 per cent, the vast majority of consumers would benefit even after tariffs are rebalanced.

One last comment regards the short-run nature of our estimated demands. The energy demand equations were conditioned on certain durable goods. This eliminates the modelling and estimation problems posed by energy-consuming durables in the demand for fuels. But the cost is that the demands, and the elasticities calculated from them, are only relevant in the short run. In the long run, households will be able to change their holdings of durables and we have not considered that possibility here. However, since consumers will adapt their behaviour in order to avoid negative impacts, any long-run substitution possibilities in durable ownership for consumers must decrease any negative impact of tariff rebalancing.

\section{CONCLUSIONS}

From the results presented in Section III, we may conclude that the rebalancing of tariffs between the fixed charge and the variable charge will have important distributional impacts. Short of avoiding the tariff rebalancing, there are several alternatives to address the distributional consequences of this change. In the first place, as argued by Burns, Crawford and Dilnot (1995), the existing welfare system could be used as a compensating instrument. Some form of energy subsidy already 
exists in the present system. Pensioners, for example, receive benefits that are linked to weather conditions as a way to compensate for higher energy bills. Programmes such as this could be expanded if negative distributional effects on some groups are to be avoided by tariff restructuring. The advantage of these programmes is that they address distributional issues through the welfare system and thus allow prices to be set by efficiency considerations only. We have shown that the compensation required by those who stand to lose from the price changes is small relative to the gains of the winners.

A second alternative is lifeline rates. Since the rebalancing of tariffs will negatively affect those households that consume small amounts of the commodity in question (for which the standing charge is a higher fraction of the total expenditure), some special tariff could be designed for small consumers.

More importantly, however, if competition increases the efficiency of gas supply, it is possible that almost all households gain even when tariffs are rebalanced. Our results show that reducing customer-related costs by 20 to 30 per cent will eliminate most of the negative distributional impacts of tariff rebalancing.

\section{BIBLIOGRAPHY}

Baker, P.. Blundell, R. and Micklewright, J. (1989), 'Modelling household energy expenditure using micro-data', Economic Journal, vol. 99, pp. 220-38.

- and Micklewright, J. (1987), 'Fuel and the Family Expenditure Survey'. Queen Mary College, Department of Economics, Discussion Paper no. 164.

Banks, J., Blundell, R. and Lewbel, A. (1996), 'Quadratic Engel curves and consumer demand', mimeo, Institute for Fiscal Studies.

Burns, P., Crawford, I, and Dilnot, A. (1995), 'Regulation and redistribution in utilities', Fiscal Studies, vol. 16, no. 4, pp. 1-22.

Feldstein, M. (1972), 'Equity and efficiency in public sector pricing: the optimal two-part tariff', Quarterly Journal of Economics, vol. 86, pp. 175-87.

Gómez-Lobo, A. (1996), 'The welfare implications of tariff rebalancing in the domestic gas market', mimeo, Institute for Fiscal Studies.

Hancock, R. and Waddams Price, C. (1995), 'Competition in the British domestic gas market: efficiency and equity', Fiscal Studies, vol. 16, no. 3, pp. 81-105.

Heckman, J. (1979), 'Sample selection bias as a specification error', Econometrica, vol. 47, pp. $153-62$.

House of Commons (1994), The Domestic Gas Market, Trade and Industry Committee, First Report, London: HMSO.

Meghir, C. and Robin, J.-M. (1992), 'Frequency of purchase and the estimation of demand systems', Journal of Econometrics, vol. 53, pp. 53-85.

Moffitt, R. (1990), 'The econometrics of kinked budget constraints', Journal of Economic Perspectives, vol. 4, pp. 119-39.

Schmalensee, R. (1981), 'Monopolistic two-part pricing arrangements', Bell Joumal of Economics, vol. 8 , pp. $445-67$. 